\title{
Pedagogia de projetos na biblioteca escolar: proposta de um modelo para o processo da pesquisa escolar
}

César Augusto Castro

\author{
Doutor em Educação, Professor do \\ Departamento de Biblioteconomia da \\ Universidade Federal do Maranhão
}

Maria Conceição Pereira de Sousa

\begin{abstract}
Especialista em Gestão de Arquivo, Professora Substituta do Departamento de Biblioteconomia da Universidade Federal do Maranhão)
\end{abstract}

Mostra a importância da pesquisa no processo de ensinoaprendizagem. Enfoca a biblioteca escolar como estimuladora da prática da pesquisa escolar, a partir da Pedagogia de Projetos. Evidencia resultados de pesquisa de campo em uma escola de São Luís-MA, dirigida a alunos, professores e ao ambiente da biblioteca da escola. Propõe um modelo para o processo de pesquisa, através do uso de projetos, a ser aplicado no âmbito da biblioteca escolar, promovendo a eficácia da construção, concretização e internalização da pesquisa.

Palavras-chave: Pesquisa escolar; Processo ensinoaprendizagem; Biblioteca escolar; Prática da pesquisa. Trabalho com projetos.

\section{Project's pedagogy in school library: proposal of a model for the process of school research}

The paper discusses the importance of the research in the educational context for the teaching-learning process. It focuses on the school library as encouragement for the practice of school research through Project's Pedagogy. It analyzes the result of a research carried out in a school of Basic Education in São Luis-MA, with the students, 
teachers and the environment of the library, to identify the process of research in the school context. A model for the process of school research is proposed through the use of projects. The model is to be applied in the context of the school library extending to the classrooms, aiming at stimulating the practice of research among students, teachers and librarians, as well as promoting the integration between them for the effectiveness of the construction and concretization of school research.

Keywords: School research; Process teach-learning; School library; Practical research; Projects with works.

Recebido em 28.12.2007 Aceito em 06.03.2008

\section{Introdução}

No começo do séc. $X X$, diante das novas necessidades de aprendizagem dos educandos no cotidiano escolar, John Dewey iniciava a discussão sobre a Pedagogia Ativa - aluno como sujeito do seu próprio conhecimento, que seria o primeiro direcionamento para a atual Pedagogia de Projetos (LEITE, 1996). Para Bomtempo et al. (2000, p. 7) Pedagogia de Projetos consiste numa "[...] concepção de posturas pedagógicas, e não meramente [...] técnica de ensino mais atrativa". Sendo assim, focaliza o desenvolvimento de uma metodologia de trabalho pedagógico que valoriza a participação do educando e do educador no processo de ensino-aprendizagem, com o objetivo de re-significar 0 espaço escolar, tornando-o rico em interações, aberto à realidade e às múltiplas dimensões (LEITE, 1996).

Demo (1997) aponta a pesquisa como recurso metodológico com propriedades para a construção da aprendizagem no processo de formação da competência humana. Por conseguinte, apesar de a pesquisa ser elemento estimulador do aprendizado no ambiente educacional, ela geralmente é usada como um ato reprodutivo executado pelo aluno, que se apropria de conteúdos de terceiros sem qualquer referência aos mesmos e com a "devida co-aprovação" do professor (CARVALHO, 2003), ocorrendo então a "pseudo-pesquisa" e a "pseudo-aprendizagem".

Neste contexto, a biblioteca escolar é irrefutavelmente necessária para reverter a prática das cópias, pois a biblioteca é considerada "[...] centro de recursos educativos, integrado ao processo de ensinoaprendizagem" (FRAGOSO, 1996, p. 78), e sua participação no currículo escolar para a busca e o uso de informação é preponderante, o que faz com que a biblioteca seja um laboratório de aprendizagem, e o bibliotecário o facilitador dessa aprendizagem.

Assim vê-se na introdução da Pedagogia de Projetos no espaço da biblioteca escolar uma tentativa de suprimir a carência de alunos e/ou professores com relação a pesquisa, haja vista que sua prática significa 
"[...] uma maneira de entender [...] para compreensão, o que implica [...] um processo de pesquisa que tenha sentido [... através de] diferentes estratégias de estudo [...]" (HERNÁNDEZ, 1998a, p. 31), tornando-se fundamental a integração do bibliotecário educador, educandos e professores nesse processo.

Portanto, após investigação descritiva, composta de pesquisa bibliográfica e de campo, uso de instrumentos de coleta de dados, como questionários de quesitos abertos e fechados, e ainda entrevista diretiva, propôs-se um modelo para o processo da pesquisa no âmbito da biblioteca escolar, através da introdução da Pedagogia de Projetos, direcionado a uma escola de Ensino Fundamental de São Luís-MA.

Para tanto, verificou-se a forma de realização da pesquisa na escola em questão; buscou-se a identificação das dúvidas/dificuldades de professores e alunos no processo de pesquisa; e estruturou-se um modelo para o uso da Pedagogia de Projetos durante o processo de pesquisa na biblioteca escolar, visando estimular a prática da pesquisa e propiciar a interação com o bibliotecário para facilitar a compreensão do ensinoaprendizagem da pesquisa.

\section{A educação através da pesquisa e mediação da biblioteca no processo da pesquisa escolar}

Braga (2002) evidencia que a melhor forma do uso do conhecimento é utilizá-lo de modo significativo e demonstrando resultados. Daí a importância da aplicação da pesquisa escolar na educação, como denota Demo (1992, p. 39):

Quem não pesquisa apenas reproduz [...]. Quem pesquisa é capaz de produzir instrumentos e procedimentos [...]. Em vez do pacote didático e curricular [utilizado na educação] como medida de ensino e da aprendizagem, é preciso criar condições de criatividade, via pesquisa, para construir soluções, principalmente diante de problemas novos.

Assim é com base nos resultados adquiridos na prática da pesquisa que o indivíduo pode refletir sobre a situação em que vive e construir novos resultados para mudar a realidade em sua volta.

Os Parâmetros Curriculares Nacionais (BRASIL, 2000) apontam que a prática da leitura deve ser sempre um meio e não um fim. Para isso, a participação da biblioteca é fundamental, devendo possuir um ambiente confortável e agradável, com acervo variado, de onde o professor possa indicar livros, mas em que também os alunos possam escolhê-los por conta própria, e até mesmo levá-los para casa.

Amplia-se então o papel da biblioteca escolar - considerada também um espaço educacional, pois além de serviço de informação para educando e educadores, a partir dos seus recursos informacionais, ela também promove a disseminação e o enriquecimento das informações recebidas e transmitidas na ambiência da escola e fora dela, tornando-se 
"[...] um núcleo central do sistema escolar e não [...] apenas uma extensão da sala de aula." (FURTADO, 2000, [p. 2]).

\section{A pedagogia de projetos no âmbito escolar}

As práticas curriculares do modelo clássico da educação - o professor como centro do saber - não atendendo mais plenamente à demanda, suscitou transformações nas escolas, que acarretaram no interrelacionamento com a sociedade, e o envolvimento dos alunos no processo de aprendizagem.

Diante desse cenário, no início do séc. XX o filósofo John Dewey propôs uma nova concepção de educação - a Pedagogia Ativa (atual Pedagogia de Projetos), que em síntese, versava sobre uma prática pedagógica onde o aluno era sujeito de seu próprio conhecimento, embasado pela aplicação de projetos no contexto escolar, visando evidenciar as experiências de vida adquiridas. No contexto atual, também é conhecida por trabalho com projetos, e tem como principais estudiosos César Coll, Josette Jolibert e Fernando Hernández, que através refletem sobre o papel e a função social da escola, o sentido das experiências escolares e sua influência na comunidade escolar, em especial nos alunos (BOMTEMPO et al., 2000).

Durante o uso da pedagogia de projetos, algumas características devem ser levadas em conta pelo educador, pois servirão de base no decorrer do processo de ensino-aprendizagem da pesquisa no ambiente escolar (BOMTEMPO et al., 2000; HERNÁNDEZ, 1998b; LEITE, 1996; LEITE; OLIVEIRA; MALDONADO, 1998):

a) atividade intencional, visando um objetivo que norteará as atividades do grupo;

b) planejamento flexível, para não haver tempo fixo nas atividades, e sim uma previsão;

c) responsabilidade e a autonomia, onde os alunos são coresponsáveis pela escolha e desenvolvimento do trabalho;

d) autenticidade e individualidade dos alunos na construção de respostas pessoais e originais;

e) valorização da experiência, significando o aproveitamento da experiência de cada aluno;

f) predomínio da cooperação, o que acarreta em ajuda mútua entre os envolvidos (professores/alunos);

g) diversificação cultural, que permite 0 trabalho com diferentes tipos de informação;

h) aprendizagem através da interação entre aprendiz e o objeto do conhecimento, visando a percepção das diversas formas e caminhos do aprendizado.

Baseando-se nos estudos de Faqueti, e de Leite sobre a temática em questão, realizou-se uma síntese das etapas da pesquisa, identificando cinco importantes etapas que configuram o processo de aprendizagem da 
pesquisa escolar na elaboração de um projeto (FAQUETI, 2002; LEITE, 1996):

a) iniciação

mobilização da curiosidade;

identificação de possíveis problemas/temas de pesquisa;

contato inicial com fontes de informação;

planejamento da pesquisa.

b) desenvolvimento

definição de estratégias para responder ao problema/tema da pesquisa;

seleção de informação;

aceitação da temática de estudo;

elucidação do projeto.

c) finalização

descrição da pesquisa;

construção de pensamento próprio;

internalização da temática da pesquisa;

aplicação da pesquisa.

d) divulgação

apreciação do resultado da pesquisa;

socialização do conhecimento;

discussão sobre os resultados obtidos na pesquisa;

promoção da auto-estima entre os participantes

e) avaliação

verbalização dos sentimentos sobre o projeto;

recapitulação dos conhecimentos adquiridos;

auto-avaliação de educandos e educadores: reflexão sobre o processo, as ações demandadas e o produto final da pesquisa; sugestões e/ou recomendações para próximos projetos.

Pode-se observar então que cada etapa descrita manifesta-se em ações praticadas pelo aluno pesquisador, e tais ações devem ser bem entendidas, internalizadas e reiniciadas a cada nova pesquisa, configurando-se assim, um processo cíclico.

\section{A prática da pesquisa em uma escola de São Luís}

A escola pesquisada atende nos turnos da manhã, tarde e noite, possuindo em 2004, um número aproximado de 8.700 alunos matriculados na Educação Formal. A Biblioteca da escola funciona das 7:00h às 22:00h e abriga um acervo composto de aproximadamente 17.000 exemplares registrados, entre livros, revistas, enciclopédias, dicionários, folhetos, mapas, manuais, entre outros, disponíveis para consulta local. $O$ intuito da pesquisa foi verificar o processo de ensino- 
aprendizagem da pesquisa escolar em sua prática real, para que através do cruzamento com informações contidas na literatura, fosse possívela elaboração de um modelo para o processo da pesquisa escolar, a partir do uso da pedagogia de projetos na biblioteca.

Dessa forma aplicou-se 87 (oitenta e sete) questionários junto a alunos da $8^{a}$ série, contendo 16 perguntas, de múltipla escolha (com permissão de marcação de mais de uma alternativa), organizadas em 3 (três) Momentos (Iniciação, Desenvolvimento e Finalização) relacionados entre si, referentes ao processo de pesquisa, bem como 9 (nove) questionários com quatro perguntas, voltados para professores da série citada, ambos com questões abertas e fechadas. Também foi realizada uma entrevista na Biblioteca da escola, com a Bibliotecária Chefe.

\subsection{Análise e interpretação dos dados}

Devido a investigação de campo ter abrangido três etapas concomitantes, as quais envolveram alunos, professores e biblioteca, entende-se que a melhor forma de compreender os dados coletados seria apreciando cada etapa separadamente, ponderando considerações individualizadas sobre elas, que convergirão para uma visão macro da temática em estudo ao final deste trabalho. Apresentam-se aqui apenas os principais resultados obtidos em campo.

\subsubsection{Percepção sobre os alunos}

No primeiro Momento (Iniciação), procurou-se identificar a liberdade dos alunos na seleção/escolha do assunto/tema para pesquisa de um trabalho. $66,0 \%$ das indicações correspondeu à distribuição do assunto por meio de sorteio ou apontamento do professor. A alternativa em que somente às vezes os alunos escolhiam o assunto obteve $20,0 \%$.

Os resultados ratificam a visão de Carvalho (2003) sobre a prédefinição de temas de pesquisa por parte dos próprios professores, sem nenhuma interferência dos discentes, já que a maioria dos alunos recebe o tema de pesquisa através de sorteio ou indicação dos professores. Isso pode desencadear para a não significação e não internalização da pesquisa para os alunos.

A este respeito, os Pârametros Curriculares Nacionais (BRASIL, 2000) deixam claro que para uma aprendizagem com significado é preciso o envolvimento do aluno em todos os sentidos. Ou seja, é fundamental motivar intimamente o aluno (estimulando sua vontade) para que haja participação e, sobretudo, mostrar-lhe a importância e a necessidade daquilo que se vai aprender.

No segundo Momento (Desenvolvimento), buscou-se verificar as atitudes e os sentimentos dos alunos durante a preparação para a redação de um trabalho, após a identificação das fontes necessárias à pesquisa. $24,0 \%$ referiram-se à leitura de vários materiais antes da escrita do trabalho. Outros $12,0 \%$ à opção alívio após o final do trabalho. Um 
percentual aproximado do anterior $(11,0 \%)$ ilustrou a alternativa escrita dos primeiros rascunhos após a escolha das fontes de pesquisa.

Conforme os dados investigados percebeu-se uma grande incidência na exploração dos recursos informacionais antes da redação de um trabalho, evidenciando a prática de diversas leituras para abstrair da literatura a interpretação e compreensão do tema, fato que refletirá na capacidade de elaboração própria destacada por Demo (1997). Em contrapartida, um relativo número de alunos afirmou redigir os primeiros rascunhos do trabalho, desconsiderando o aprofundamento nas leituras necessárias para uma boa aprendizagem do conteúdo do tema.

Para conhecer a forma como os alunos redigem um trabalho solicitado, foi realizado outro questionamento. 35,0\% correspondeu à opção fazer a interpretação das fontes de pesquisa e escrever conforme o compreendido. Outros $27,0 \%$ à alternativa copiar parcialmente as informações das fontes de pesquisa e completar com o que compreenderam. A opção escrever mudando algumas palavras das fontes de pesquisa representou $21,0 \%$ do total obtido. A alternativa de reprodução integral de todas as informações relevantes das fontes de pesquisa obteve $15,0 \%$.

Refletindo-se sobre os achados, percebeu-se que a maioria dos alunos parecia redigir suas pesquisas de forma acertada e condizente com o que a literatura pede. Entretanto, verificando-se as demais opções assinaladas, estas apresentaram um grau relativamente alto de indicação (cópia integral ou parcial das fontes), fato que deverá ser acompanhado com minúcia pelos educadores, posto que não se pode deixar que os alunos habituem-se em copiar idéias alheias como sendo suas, corroborando o citado por Carvalho (2003). O que deve ser deixado bem claro aos educandos é que o ato de copiar deverá ser transfigurado para o ato de citar, devidamente sustentado pela compreensão e expressão verbal ou escrita do que foi citado.

No terceiro Momento (Finalização), indagou-se sobre o costume do professor trabalhar projetos em sala de aula, bem como solicitou-se exemplos. Considerando-se o total de 87 respondentes, obteve-se $88,0 \%$ da opção SIM, confirmando que seus professores trabalham projetos no cotidiano da sala de aula. Porém, deste valor, três não fizeram a exemplificação solicitada. A opção NÃ̃o foi indicada por 10,0\% dos alunos, conforme Tabela 1. 
TABELA 1 - Costume do professor trabalhar projetos na sala de aula

\begin{tabular}{|c|c|c|c|}
\hline Opções & Qt. & Exemplos citados & $\%$ \\
\hline Sim & 76 & $\begin{array}{l}\text { Fome de quê?; Religiões; } \text { Culminância }^{1} \text {; Debates; Seminários; } \\
\text { Conhecendo mais a nossa cidade; Fome zero; Arte grega e romana; } \\
\text { Aspectos de outros países; Simulados; Base de Alcântara; Roma e } \\
\text { outros; Apresentações de trabalhos; Fulano, Ciclano e Beltrano } \\
\text { (nomes dos professores) }{ }^{2} \text {; Trabalho de artes sobre música; Desfile e } \\
\text { outros; Trabalho em equipe; Projetos sobre música, peças teatrais; } \\
\text { Dinâmicas, jogos sobre o assunto; Teatro; Arte de conviver; Visita ao } \\
\text { museu, circo, teatro, praia; Trabalhos, pesquisas; Filosofia; Ética; } \\
\text { Recortes com protestos por melhorias no ensino, outros; Maquetes; } \\
\text { Feira cultural; Trabalhos dos capítulos; Diálogos, ida à sala de } \\
\text { computação, eventos esportivos, exposição de trabalhos; História, } \\
\text { geografia; Peças de artes sobre teatro; Músicas; Trabalho de produção } \\
\text { textual, artes, geografia; Vários, dependendo da aula; Passeios; }\end{array}$ & 88,0 \\
\hline Não & 9 & 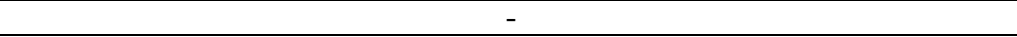 & 10,0 \\
\hline Branco & 2 & - & 2,0 \\
\hline \multicolumn{2}{|c|}{ Total } & 87 & 100 \\
\hline
\end{tabular}

FONTE: SOUSA, (2004).

De acordo com a Tabela 1, a maioria dos alunos afirmou que os professores trabalham projetos em turma. Todavia, tomando-se como referência os exemplos citados, verificou-se a confusão destes alunos a respeito do que seja um projeto, já que das exemplificações dadas, poucas enquadram-se com o que foi solicitado. Na verdade, entende-se que grande parte refere-se a pelo menos um dos itens citados a seguir: procedimentos didáticos e/ou tarefa escolar; nomes de disciplinas; eventos escolares; nomes dos professores; exemplos evasivos.

Neste sentido, apenas os exemplos a seguir podem talvez configurar-se como projeto: - fome de quê?; - religiões; - conhecendo mais nossa cidade; - arte grega e romana; - fome zero; - Base de Alcântara, entre outros. Assim, diante da mistura informacional constatada pelos resultados obtidos, infere-se que os alunos precisam ser mais bem orientados sobre o que é um projeto de pesquisa e sua diferença de um trabalho disciplinar, para que possam inclusive aproveitar do conhecimento metodológico do primeiro para subsidiar a organização e a elaboração do segundo, que também se reveste do processo de pesquisa.

\subsubsection{Percepção sobre os professores}

A segunda etapa da pesquisa constituiu-se da aplicação de questionário para os professores participantes da amostra, buscando identificar a relação desses com a pesquisa no ambiente escolar. O uso da pesquisa como parte do processo ensino-aprendizagem de sala de aula foi questionado, e 78,0\% dos respondentes informaram que faziam uso.

Sabendo-se que a biblioteca pode interferir positivamente nas práticas pedagógicas, indagou-se sobre a biblioteca da escola, obtendo-se

1 Segundo conversa informal com vários respondentes durante a devolução do questionário, identificou-se que o termo Culminância refere-se na verdade à Feira Científico-cultural da escola

2 Os nomes dos professores aqui citados foram substituídos a fim de preservar suas identidades. 
um percentual de $32,0 \%$ para alternativa que a considera essencial para o processo ensino-aprendizagem, disseminação de conhecimento, estímulo da leitura, entre outros.

Outros $16,0 \%$ representaram também ao mesmo tempo as seguintes opções: - orienta seus alunos a freqüentá-la, mas pouco ou nada conhece sobre seu acervo, produtos e serviços oferecidos; - mantém bom relacionamento com a bibliotecária, promovendo aulas no recinto para uso de suas fontes informacionais.

As respostas com maior número de indicações evidenciam o pensamento de Furtado (2000), que traduz a biblioteca escolar como núcleo central do sistema escolar. Porém, faz-se uma ressalva àqueles professores que, apesar de orientarem seus alunos a freqüentar a biblioteca da escola, permanecem alheios à sua existência, pois revelam pouco ou nada conhecer sobre sua realidade.

\subsubsection{Percepção sobre a biblioteca da escola}

$\mathrm{Na}$ etapa final da pesquisa de campo investigou-se a biblioteca da escola, por meio de entrevista dirigida à Chefe da biblioteca, com perguntas que versaram principalmente sobre: produtos e serviços oferecidos; orientação ao aluno durante uma pesquisa; interação com professores; envolvimento nos projetos da escola.

Sobre os produtos e serviços oferecidos, a bibliotecária revelou que a biblioteca realiza e disponibiliza: Serviço de referência, pesquisa local, Incentivo à leitura para os alunos da Educação Infantil e Ensino Fundamental I, programações em datas comemorativas com atividades de rodas de leitura, manipulação de fantoches, entre outros. Refletindo-se sobre essas informações, fica nítido a superficialidade das respostas dadas, pois algumas não se enquadram nem como produto nem como serviço, mas sim como objetivo a ser alcançado, estratégias a serem praticadas pela biblioteca para estimular leitores reais e potenciais à prática de leitura.

Indagou-se ainda, a respeito da orientação dada aos usuários durante a pesquisa na biblioteca, obtendo-se o seguinte: a orientação para pesquisa é realizada diretamente com os alunos através do Setor de Referência, após a identificação da temática da pesquisa, onde serão indicadas as possíveis fontes com o referido tema. A bibliotecária também informou que a interação entre os professores e a biblioteca ocorre através da realização de aulas no local, que devem ser marcadas com dois dias de antecedência. Quanto à participação da biblioteca nos projetos desenvolvidos na escola, a resposta obtida foi que a biblioteca, além de fornecer suporte informacional aos projetos, oferece seu espaço físico. Contudo, contatou-se na literatura que esta pode fazer e oferecer muito mais. 


\section{Proposta de modelo para o processo de pesquisa na biblioteca de uma escola de São Luís}

A pesquisa escolar deve ser entendida com uma ação em que os sujeitos procuram respostas ou reorganizam seus conhecimentos para, em novos arranjos, agregar valores (FAQUETI, 2002). Assim, refletindo-se sobre o resultado obtido em campo, de que a pesquisa precisa ser mais bem desenvolvida por alunos, professores e biblioteca, ratificou-se a necessidade de um modelo para o processo da mesma, que tanto estimule a aprendizagem quanto suscite a integração entre os participantes. Por isso, propôs-se um modelo para o processo de pesquisa na biblioteca escolar para cotidianizar, otimizar e dinamizar a pesquisa escolar por meio de projetos. A estrutura desse modelo apresenta-se em 5 etapas, já detalhadas anteriormente, e está respaldada nas teorias de Faqueti (2002) e Leite (1996).

Interligadas entre si, as etapas desmembram-se em ações específicas a serem desenvolvidas progressivamente pelos participantes do projeto, num ciclo de retro-alimentação, pois, em caso de ruído na execução do projeto, tem-se a possibilidade de retornar a quaisquer das etapas ou a seus respectivos desmembramentos para modificações desejadas. Portanto, devem ser devidamente planejadas, executadas, divulgadas e posteriormente avaliadas, permitindo aos seus aplicadores condições de previsão, programação e realização do projeto.

Nos Quadros de 1 a 5 (em ANEXO) tem-se uma melhor visualização da descrição individualizada desses procedimentos em cada etapa.

Depois do devido entendimento sobre a estrutura e os procedimentos descritos, demonstra-se na Figura 1 (em ANEXO) acima o modelo proposto para o processo da pesquisa escolar, viabilizado na biblioteca através de projetos.

Trata-se da convenção elaborada das cinco etapas de um projeto, onde educadores e educandos podem visualizar todo o processo de elaboração de um projeto de pesquisa, voltado para o processo ensinoaprendizagem, permitindo a melhor compreensão de sua execução e ainda, a integração dos envolvidos.

\section{Conclusão}

A utilização da pedagogia de projetos surge como uma resignificação do espaço de aprendizagem, propondo a organização do processo de construção de saberes e competências, principalmente no que concerne à pesquisa, aonde o trabalho com projetos vem configurar, dentro de suas características e etapas, uma nova roupagem para a compreensão especialmente dos alunos sobre conhecimentos internos e externos do meio educacional, podendo ser amplamente utilizado no âmbito da biblioteca escolar.

Os resultados dessa pesquisa demonstraram que os alunos, embora dizendo-se conhecedores do processo de pesquisa, sentem dificuldades, principalmente na sua finalização (redação), utilizando-se, por 
conseguinte, do velho hábito da reprodução textual. Confundem-se sobre o que seja pesquisa para trabalhos escolares e projetos de pesquisa no real sentido da palavra.

Já os professores confirmaram sentir dúvidas sobre o processo de pesquisa, porém, ainda assim repassam tudo o que sabem para seus alunos. Poucos têm conhecimento sobre os serviços e produtos oferecidos pela biblioteca da escola, ou ainda não colaboram com sugestões para o acervo ou execuções de atividades nesse ambiente. Percebeu-se também, o fraco impulso para uma educação continuada ou conhecimento da produção informacional de seus pares.

No que tange à biblioteca, esta tem que mostrar-se mais participativa no processo de pesquisa dos educandos, no sentido de envolver-se mais especificamente com os conteúdos curriculares e pedagógicos, para então subsidiar educadores e educandos em suas pesquisas, deixando de ser indicadora de fontes de informação para ser orientadora, estimuladora e divulgadora da pesquisa e de seus pesquisadores, ampliando desta forma, a interação aluno/professor/biblioteca.

\section{Referências}

BOMTEMPO, L. et al. Os alunos investigadores. Caderno Amae: pedagogia de projetos. Belo Horizonte, p. 6-11, out. 2000. (Ed. Especial).

BRAGA, R. Como será o futuro da educação? Aprender virtual, Marília, n. 3, p. 22-30, maio/jun. 2002.

BRASIL. Ministério da Educação. Secretaria de Educação Fundamental. Parâmetros curriculares nacionais: introdução. 2.ed. Brasília: DP \& A, 2000. v. 1.

CARVALHO, E. F. Desafio da escola: ensinar a pesquisar. Crônicas e informações. Disponível em: <http://www.onlife.com.br/elivil/ensaio1.htm>. Acesso em: 20 set. 2003.

DEMO, P. Pesquisa: princípio científico e educativo. 3.ed. São Paulo: Cortez: Autores Associados, 1992. 120p. (Biblioteca de Educação. Série 1 - Escola; v. 14). 1997. 120p.

Educar pela pesquisa. 2.ed. Campinas, SP: Autores Associados,

FAQUETI, M. F. O bibliotecário como sujeito ativo no processo de ensinoaprendizagem através da pesquisa escolar: proposta de um modelo. 2002. 137f. Dissertação (Mestrado em Engenharia de Produção) - Programa de Pós-Graduação em Engenharia de Produção, UFSC, Florianópolis, 2002.

FRAGOSO, G. M. Casas de livros ou simplesmente... bibliotecas. Presença Pedagógica. Belo Horizonte, v. 2, n. 12, p. 74-79, nov./dez. 1996.

FURTADO, C. C. A biblioteca escolar no sistema educacional da sociedade da informação segundo proposições de Masuda. In: CONGRESSO 
BRASILEIRO DE BIBLIOTECONOMIA E DOCUMENTAÇÃO, 19., Porto Alegre. Anais... Porto Alegre: Associação Rio-grandense de Bibliotecários, 2000. CD-ROM.

HERNÁNDEZ, F. Repensar a função da escola a partir dos projetos de trabalho. Pátio, Porto Alegre, n.6, p.26-31, ago./out. 1998a. . Transgressão e mudança na educação: os projetos de trabalho. Porto Alegre: ArtMed, 1998b. 152p.

LEITE, L. H. A. Pedagogia de projetos: intervenção no presente. Presença Pedagógica. Belo Horizonte, v. 2, n. 8, p. 24-33, mar./abr. 1996.

LEITE, L. H. A.; OliVeirA, M. E. P. de; MALDONADO, M. D. Projetos de trabalho. In: BRASIL. Ministério da Educação e do Desporto. Secretaria de Educação à Distância. Diários: projetos de trabalho. Brasília: MEC/SEED, 1998. p. 57-98. (Cadernos da TV Escola. PCN na Escola; n. 3). Disponível em: <http://www.mec.gov.br/seed/tvescola/pdf/diarios.pdf>. Acesso em: set. 2003.

SOUSA, M. C. P de. Pedagogia de projetos na biblioteca escolar: proposta de modelo para o processo de pesquisa na biblioteca do CINTRA através de projetos. 2004. 106f. Monografia (Graduação em Biblioteconomia) Departamento de Biblioteconomia, UFMA, São Luís, 2004.

\section{ANEXOS}


QUADRO 1

Procedimentos didáticos: etapa iniciação

Fonte: Adaptado de Faqueti (2002)

\begin{tabular}{|c|c|c|c|c|c|c|}
\hline \multirow{3}{*}{ ETAPAS } & \multicolumn{6}{|c|}{ PROCEDIMENTOS } \\
\hline & \multirow{2}{*}{ OBJETIVOS } & \multicolumn{2}{|c|}{ CONTEÚDOS } & \multicolumn{2}{|c|}{1 AÇÕES DOS EDUCADORES } & \multirow{2}{*}{$\begin{array}{l}\text { RESULTADOS } \\
\text { DESEJADOS }\end{array}$} \\
\hline & & Práticos & Subjetivos & Professores & \begin{tabular}{|l} 
Bibliotecários \\
\end{tabular} & \\
\hline & $\begin{array}{l}\text { Favorecer a } \\
\text { interação do } \\
\text { grupo com os } \\
\text { objetos } \\
\text { investigados } \\
\text { (fatos ou } \\
\text { fenômenos), } \\
\text { suscitando a } \\
\text { curiosidade e } \\
\text { formulação de } \\
\text { questões, para } \\
\text { estabelecer os } \\
\text { planos do } \\
\text { projeto. }\end{array}$ & $\begin{array}{l}\text { Noções sobre } \\
\text { pesquisa } \\
\text { (conceitos, } \\
\text { tipos, } \\
\text { processo, etc.); } \\
\text {. Identificação } \\
\text { das fontes de } \\
\text { informação } \\
\text { primária, } \\
\text { secundária e } \\
\text { terciária } \\
\text {. Métodos de } \\
\text { coleta de } \\
\text { dados. }\end{array}$ & $\begin{array}{l}\text { Motivação da } \\
\text { curiosidade e } \\
\text { auto-estima; } \\
\text {. Interação dos } \\
\text { grupos e } \\
\text { exposição de } \\
\text { dúvidas/troca de } \\
\text { informação. }\end{array}$ & $\begin{array}{l}\text { Apresentar ou acatar temas } \\
\text { trazidos pelos alunos; } \\
\text {. Promover o contato gradual } \\
\text { com a temática, possibilitando } \\
\text { diversas explorações; } \\
\text { Oferecer noções de } \\
\text { pesquisa; } \\
\text {. Criteriorizar junto com os } \\
\text { alunos, parâmetros de } \\
\text { pesquisa: objetivos, métodos, } \\
\text { forma de apresentação, } \\
\text { cronograma, divulgação e } \\
\text { avaliação processual e final. }\end{array}$ & $\begin{array}{l}\text {. Explanar para professores sobre } \\
\text { o processo de pesquisa, tipos de } \\
\text { fontes informacionais, } \\
\text { referenciação, estratégias de } \\
\text { busca e coleta de dados; } \\
\text {. Reforçar para o aluno, discurso } \\
\text { sobre a pesquisa; } \\
\text {. Organizar treinamentos } \\
\text { específicos para atender às } \\
\text { necessidades de alunos e } \\
\text { professores, e atualizar /e } \\
\text { elaborar produtos que facilitem o } \\
\text { acesso às informações da } \\
\text { biblioteca. }\end{array}$ & $\begin{array}{l}\text { Promover a relação } \\
\text { intrínseca entre sujeitos e } \\
\text { objetos a serem } \\
\text { investigados, por meio da } \\
\text { motivação e interesse pela } \\
\text { pesquisa, aguçando a } \\
\text { curiosidade e o senso } \\
\text { crítico para } \\
\text { questionamentos, busca de } \\
\text { informações gerais e } \\
\text { escolhas preliminares dos } \\
\text { possíveis temas dos } \\
\text { projetos a serem } \\
\text { pesquisados. }\end{array}$ \\
\hline
\end{tabular}


QUADRO 2

Procedimentos didáticos: etapa desenvolvimento

\begin{tabular}{|c|c|c|c|c|c|c|}
\hline \multirow{3}{*}{ ETAPAS } & \multicolumn{6}{|c|}{ PROCEDIMENTOS } \\
\hline & \multirow[t]{2}{*}{ OBJETIVOS } & \multicolumn{2}{|c|}{1.1 CONTEÚDOS } & \multicolumn{2}{|c|}{2 AÇÕES DOS EDUCADORES } & \multirow{2}{*}{$\begin{array}{l}\text { RESULTADOS } \\
\text { DESEJADOS }\end{array}$} \\
\hline & & Práticos & Subjetivos & Professores & \begin{tabular}{|l|} 
Bibliotecários \\
\end{tabular} & \\
\hline & $\begin{array}{l}\text { Aumentar a } \\
\text { bagagem } \\
\text { informacional } \\
\text { do aluno a } \\
\text { respeito do } \\
\text { tema em } \\
\text { estudo, através } \\
\text { da delimitação } \\
\text { do foco central } \\
\text { da pesquisa. }\end{array}$ & $\begin{array}{l}\text {. Estabelecer } \\
\text { estratégias para } \\
\text { busca e uso da } \\
\text { informação; } \\
\text { Seleção das } \\
\text { fontes } \\
\text { informacionais e } \\
\text { escolha de tema } \\
\text { entre os } \\
\text { propostos na } \\
\text { etapa anterior. }\end{array}$ & $\begin{array}{l}\text { Descobrir } \\
\text { idéias; } \\
\text {. Interagir com os } \\
\text { indivíduos; } \\
\text {. Reforçar a } \\
\text { criticidade e } \\
\text { criatividade; } \\
\text {. Compreender e } \\
\text { respeitar a } \\
\text { diversidade de } \\
\text { pensamento. }\end{array}$ & $\begin{array}{l}\text { Observar a evolução da } \\
\text { busca e o uso das } \\
\text { informações pesquisadas, } \\
\text { propiciando liberdade para } \\
\text { escolha das fontes, } \\
\text { ampliando a bagagem de } \\
\text { conteúdos e experiências } \\
\text { adquiridas; } \\
\text { Orientar a formulação do } \\
\text { foco da pesquisa, através } \\
\text { da delimitação do tema. }\end{array}$ & $\begin{array}{l}\text { Mediar a busca e o uso de } \\
\text { informação na biblioteca, } \\
\text { executando estratégias de busca, } \\
\text { seleção e escolha das fontes junto } \\
\text { com os alunos e professores, } \\
\text { efetuando, se preciso, } \\
\text { intervenções individuais ou } \\
\text { coletivas, através de aulas } \\
\text { específicas ou conversa informal. }\end{array}$ & $\begin{array}{l}\text {. Escolha do tema; } \\
\text {. Formulação do foco } \\
\text { central da pesquisa com } \\
\text { criticidade e criatividade; } \\
\text {. Investigação temática; } \\
\text {. Senso de organização das } \\
\text { idéias. }\end{array}$ \\
\hline
\end{tabular}

Fonte: Adaptado de Faqueti (2002). 
QUADRO 3

Procedimentos didáticos: etapa finalização

\begin{tabular}{|c|c|c|c|c|c|c|}
\hline \multirow{3}{*}{ ETAPAS } & \multicolumn{6}{|c|}{ PROCEDIMENTOS } \\
\hline & \multirow[t]{2}{*}{ OBJETIVOS } & \multicolumn{2}{|l|}{ CONTEÚDOS } & \multicolumn{2}{|c|}{3 AÇÕES DOS EDUCADORES } & \multirow{2}{*}{$\begin{array}{l}\text { RESULTADOS } \\
\text { DESEJADOS }\end{array}$} \\
\hline & & Práticos & Subjetivos & Professores & Bibliotecários & \\
\hline & $\begin{array}{l}\text { Formatar a redação } \\
\text { da pesquisa ( uso e } \\
\text { organização dos } \\
\text { conhecimentos } \\
\text { pessoais anteriores } \\
\text { e fontes } \\
\text { pesquisadas), } \\
\text { formalizando o pré- } \\
\text { estabelecido no } \\
\text { início do projeto. }\end{array}$ & $\begin{array}{l}\text {. Discussão das } \\
\text { informações } \\
\text { obtidas para início } \\
\text { da redação da } \\
\text { pesquisa; } \\
\text {. Formalização da } \\
\text { pesquisa através } \\
\text { da redação do } \\
\text { trabalho; } \\
\text {. Referenciação das } \\
\text { fontes consultadas. }\end{array}$ & $\begin{array}{l}\text {. Organização, } \\
\text { coerência e } \\
\text { coesão das } \\
\text { informações; } \\
\text {. Criatividade; } \\
\text {. Criticidade; } \\
\text {. Capacidade de } \\
\text { interpretação e } \\
\text { compreensão. }\end{array}$ & $\begin{array}{l}\text {. Orientar a escrita final do } \\
\text { trabalho de acordo com os } \\
\text { parâmetros preliminares } \\
\text { estabelecidos para } \\
\text { demonstração da pesquisa. }\end{array}$ & $\begin{array}{l}\text { Auxiliar na apresentação } \\
\text { final da pesquisa, } \\
\text { indicando possíveis } \\
\text { recursos; } \\
\text { Orientar a referenciação } \\
\text { das fontes. }\end{array}$ & $\begin{array}{l}\text {. Redação da } \\
\text { pesquisa conforme } \\
\text { normas definidas, } \\
\text { de forma crítica e } \\
\text { criativa, } \\
\text { demonstrando a } \\
\text { visão e o } \\
\text { entendimento das } \\
\text { fontes pesquisadas. }\end{array}$ \\
\hline
\end{tabular}

Fonte: Adaptado de Faqueti (2002). 
QUADRO 4

Procedimentos didáticos: etapa divulgação

\begin{tabular}{|c|c|c|c|c|c|c|}
\hline \multirow{3}{*}{ ETAPAS } & \multicolumn{6}{|c|}{ PROCEDIMENTOS } \\
\hline & \multirow[t]{2}{*}{ OBJETIVOS } & \multicolumn{2}{|l|}{ CONTEÚDOS } & \multicolumn{2}{|c|}{ AÇÕES DOS EDUCADORES } & \multirow{2}{*}{$\begin{array}{c}\text { RESULTADOS } \\
\text { DESEJADOS }\end{array}$} \\
\hline & & Práticos & Subjetivos & Professores & Bibliotecários & \\
\hline & $\begin{array}{l}\text { Divulgar os } \\
\text { resultados para a } \\
\text { sala de aula ou à } \\
\text { comunidade } \\
\text { escolar, visando a } \\
\text { apreciação das } \\
\text { ações } \\
\text { desenvolvidas. }\end{array}$ & $\begin{array}{l}\text { Exposição oral e } \\
\text { escrita dos } \\
\text { resultados obtidos } \\
\text { na pesquisa, } \\
\text { partindo-se da } \\
\text { redação do projeto e } \\
\text { experiência } \\
\text { vivenciada na } \\
\text { pesquisa. }\end{array}$ & $\begin{array}{l}\text {. Exercício do } \\
\text { hábito de } \\
\text { expressão e } \\
\text { comunicação } \\
\text { diante de um } \\
\text { público. }\end{array}$ & $\begin{array}{l}\text { Fornecer dicas para } \\
\text { apresentação oral e visual } \\
\text { da pesquisa. }\end{array}$ & $\begin{array}{l}\text { Sugerir formas de } \\
\text { divulgação dos resultados } \\
\text { como jornal ou boletim, } \\
\text { painéis, palestras, entre } \\
\text { outros, incentivando o } \\
\text { trabalho realizado. }\end{array}$ & $\begin{array}{l}\text { Apreciação do } \\
\text { produto final. }\end{array}$ \\
\hline
\end{tabular}

Fonte: Adaptado de Faqueti (2002). 
QUADRO 5

Procedimentos didáticos: etapa avaliação

\begin{tabular}{|c|c|c|c|c|c|c|}
\hline \multirow{3}{*}{ ETAPAS } & \multicolumn{6}{|c|}{ PROCEDIMENTOS } \\
\hline & \multirow[t]{2}{*}{ OBJETIVOS } & \multicolumn{2}{|l|}{4.1 CONTEÚDOS } & \multicolumn{2}{|c|}{5 ACÕES DOS EDUCADORES } & \multirow{2}{*}{$\begin{array}{c}\text { RESULTADOS } \\
\text { DESEJADOS }\end{array}$} \\
\hline & & Práticos & Subjetivos & Professores & Bibliotecários & \\
\hline & $\begin{array}{l}\text { Avaliar todo o } \\
\text { processo } \\
\text { vivenciado pelos } \\
\text { educandos, bem } \\
\text { como o produto } \\
\text { final obtido, } \\
\text { permitindo que os } \\
\text { envolvidos se auto- } \\
\text { avaliem, visando } \\
\text { aperfeiçoar ou } \\
\text { ainda sugerir novas } \\
\text { pesquisas sempre } \\
\text { que necessário. }\end{array}$ & $\begin{array}{l}\text { Qualidade do } \\
\text { produto com relação } \\
\text { à criticidade e } \\
\text { criatividade } \\
\text { transmitidas; } \\
\text {. Validade do } \\
\text { conteúdo; } \\
\text {. Adequação do } \\
\text { produto ao padrão } \\
\text { estabelecido. }\end{array}$ & $\begin{array}{l}\text { Participação; } \\
\text {. Envolvimento com a } \\
\text { pesquisa; } \\
\text {. Entrosamento com } \\
\text { o grupo para troca de } \\
\text { informações; } \\
\text {. Exposição das } \\
\text { limitações e } \\
\text { dificuldades } \\
\text { encontradas ou } \\
\text { sugestão de } \\
\text { possíveis mudanças } \\
\text { para um próximo } \\
\text { projeto. }\end{array}$ & $\begin{array}{l}\text {. Facilitar o gerenciamento } \\
\text { da experiência com a } \\
\text { pesquisa; } \\
\text {. Propiciar aos alunos e } \\
\text { educadores envolvidos a } \\
\text { oportunidade de } \\
\text { auto-avaliação sobre o } \\
\text { processo de pesquisa e o } \\
\text { produto final, considerando } \\
\text { os aspectos definidos no } \\
\text { início do projeto; } \\
\text {. Promover a generalização } \\
\text { da experiência de } \\
\text { aprendizagem obtida com o } \\
\text { projeto, almejando o } \\
\text { contato do educando com a } \\
\text { responsabilidade por seu } \\
\text { aprendizado; } \\
\text {. Favorecer aos educandos } \\
\text { e educadores a } \\
\text { oportunidade de apreciação } \\
\text { do produto final, } \\
\text { incentivando futuras } \\
\text { pesquisas. }\end{array}$ & $\begin{array}{l}\text { Participar no } \\
\text { processo avaliativo da } \\
\text { pesquisa escolar; } \\
\text {. Oferecer suporte } \\
\text { para solução dos } \\
\text { possíveis problemas/ } \\
\text { dificuldades } \\
\text { encontradas no } \\
\text { processo da pesquisa. }\end{array}$ & $\begin{array}{l}\text {. Autenticar o } \\
\text { processo construtivo } \\
\text { do conhecimento } \\
\text { através do } \\
\text { somatório da } \\
\text { pesquisa com as } \\
\text { aprendizagens } \\
\text { adquiridas em } \\
\text { experiências } \\
\text { anteriores. }\end{array}$ \\
\hline
\end{tabular}

Fonte: Adaptado de Faqueti (2002). 
Figura 1 - Procedimentos didáticos: etapa avaliação

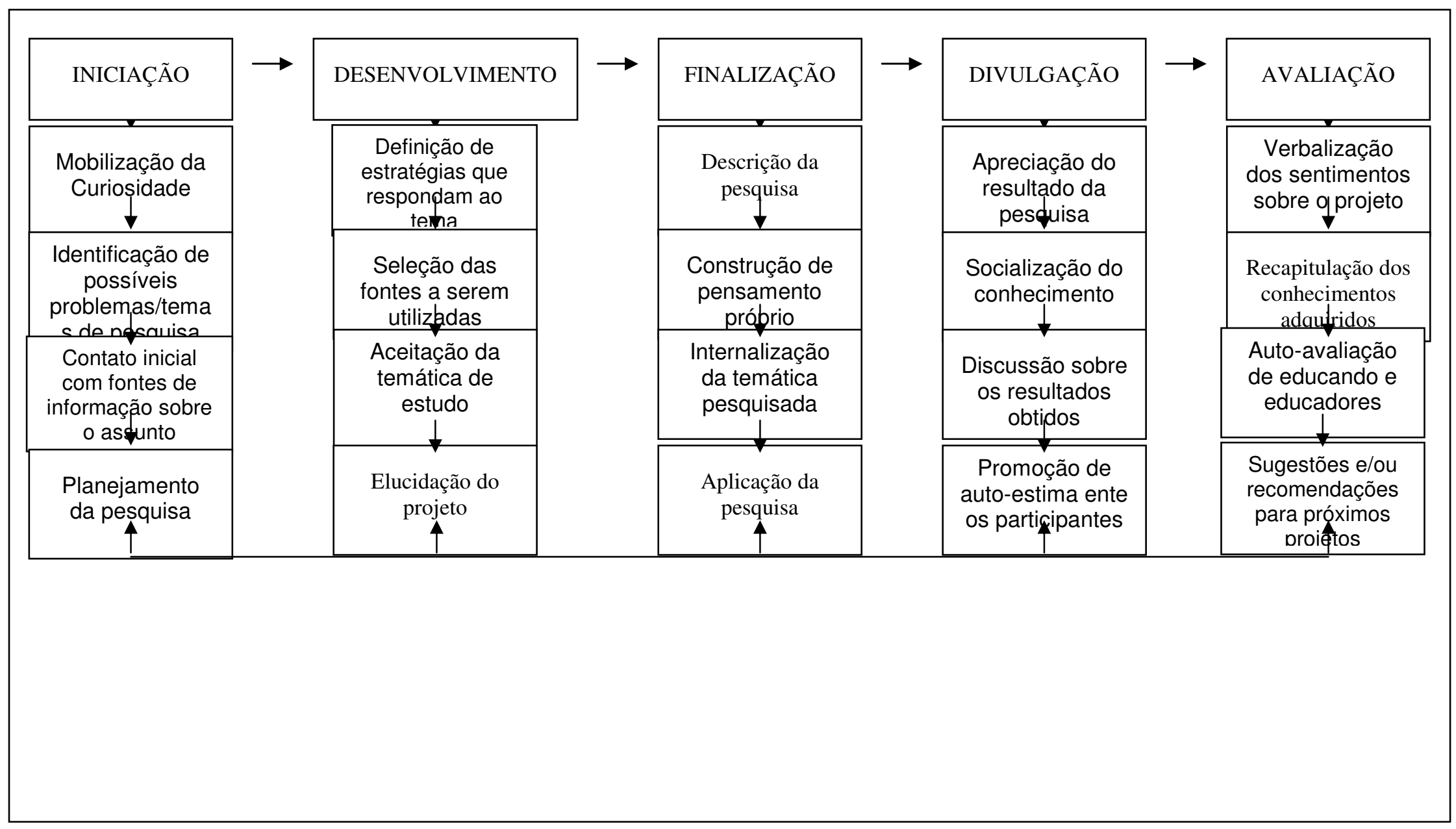

